\title{
Cerebral and gonadal aromatase expressions are differently affected during sex differentiation of Pleurodeles walt
}

\author{
Sandra Kuntz, Amand Chesnel, Stéphane Flament and Dominique Chardard \\ EA3442 Génétique, Signalisation, Différenciation, Université Henri Poincaré-Nancy I, Faculté des Sciences, BP 239, 54506 Vandoeuvre-lès-Nancy \\ Cedex, France \\ (Requests for offprints should be addressed to S Flament, Université Henri Poincaré-Nancy I, Faculté des Sciences, EA3442, Entrée 1B, 9ème étage, \\ Boulevard des Aiguillettes, BP 239, 54506 Vandoeuvre-lès-Nancy Cedex, France; Email : stephane.flament@ persmail.uhp-nancy.fr)
}

\begin{abstract}
In vertebrates, sex is determined essentially by two means, genetic factors located on sex chromosomes and epigenetic factors such as temperature experienced by the individual during development. Steroids, especially estrogens, are clearly involved in gonadal differentiation in non-mammalian vertebrates. In this regard, the expression of the estrogen-producing enzyme, aromatase, has been shown to be temperature-sensitive in species where temperature can reverse sex differentiation, especially in our model, the amphibian Pleurodeles waltl. We investigated here the regulation of aromatase expression in the brain during sex differentiation in Pleurodeles. We first isolated a brain isoform of aromatase mRNA which differs in its $5^{\prime}$ untranslated region from the isoform previously isolated from adult gonads. In adult Pleurodeles, the brain isoform is mainly expressed in brain tissue while the other isoform is gonad specific. Thus, regulation of aromatase expression in $P$. waltl could occur by alternative splicing of non-coding exon 1 as previously described in mammals. We then investigated aromatase expression in the brain of male and female larvae and found no differences with regard to sex. Measures of aromatase activity in the brain also showed no differences between sexes at larval stages whereas activity markedly increases in the ovary concomitant with the start of gonadal differentiation. These results support the hypothesis that aromatase could be a target of a temperature-sensitive sex-reversing effect in the gonads but not in the brain.
\end{abstract}

Journal of Molecular Endocrinology (2004) 33, 717-727

\section{Introduction}

The urodele amphibian, Pleurodeles waltl, is an interesting model for the study of vertebrate sex differentiation because this phenomenon displays a genetic regulation which can be overridden by temperature in this species (Chardard et al. 2004). Indeed, sex determination obeys female heterogamety: males have ZZ sex chromosomes and females have ZW sex chromosomes. However, when $\mathrm{ZW}$ larvae are reared at $32{ }^{\circ} \mathrm{C}$ during a temperature-sensitive period (TSP) ranging from stage 42 to stage 54, they differentiate into functional neomales (Dournon \& Houillon, 1985).

As observed in other non-mammalian vertebrates, steroid hormones and the estrogen- synthesizing enzyme, aromatase, play a key role in $P$. waltl sex differentiation (Kuntz et al. 2003a). Addition of estradiol or aromatizable androgens such as testosterone to the rearing water, induces male-to-female sex reversal (Gallien 1962, Chardard et al. 2003). Conversely, nonaromatizable androgens, such as dihydrotestosterone, as well as aromatase inhibitors, have no effect on ZZ larvae but drive ZW larvae to differentiate as males (Chardard \& Dournon, 1999, Chardard et al. 2003). Aromatase activity measurements in gonad-mesonephros complexes revealed a higher activity in ZW larvae than in their $\mathrm{ZZ}$ counterparts; this difference appears in the last stages of TSP (Chardard et al. 1995). High or low aromatase activity is also concordant with ovarian or testicular 
differentiation during estradiol- or aromatase inhibitor-induced sex reversal (Kuntz et al. 2003a).

The role of steroids in the sex differentiation process in $P$. waltl is also highlighted by temperature-induced sex reversal. For instance, estradiol is able to counteract the masculinizing effect of temperature (Zaborski 1986) and besides, the increase in aromatase activity that occurs in control ZW larvae from stage 52 is not observed in heat-treated ZW larvae (Chardard et al. 1995). In order to determine if this could be the result of different transcription levels, we have recently cloned the gene encoding $P$. waltl $\mathrm{P} 450$-aromatase from adult gonads (Kuntz et al. 2003b). We have found a twofold decrease in aromatase expression in heat-treated versus control ZW larvae at stage 54 (Kuntz et al. 2003b), suggesting that posttranslational events are also probably able to explain the high difference (40-fold) in enzymatic activity that is usually observed at this stage (Chardard et al. 1995).

The relationship between steroids and temperature is also obvious in reptiles with temperaturedependent sex determination (TSD). In this case, the temperature experienced by the egg during a specific window of development establishes the sex of the individual. Incubation temperature is translated into an endocrine signal, which directs the sex determination process (Crews et al. 1994). The molecular link between temperature and steroid production is unknown but temperature is hypothesized to regulate aromatase expression. The latter determines the steroidogenic environment of the gonads leading to either ovary or testis differentiation, depending on the concentration of estrogens (and androgens). However, in some species, aromatase mRNA is not observed in the genital ridge or in the differentiating gonads during the TSP: the sole aromatase activity detected in the gonad is observed after the temperature-sensitive window in the red-eared slider turtle, Trachemys scripta (Thomas et al. 1992, Willingham et al. 2000) and Lepidochelys olivacea (Salame-Mendez et al. 1998) as well as in the crocodilians Alligator mississipiensis (Smith et al. 1995, Milnes et al. 2002) and Crocodylus porosus (Smith \& Joss 1994). This suggests that during early sex differentiation in these TSD species, steroids could have an extragonadal origin.

In addition to the gonads, aromatase is mainly expressed in the brain in which estrogen synthesis occurs in several areas. Indeed, aromatase has been detected in the brain of all vertebrates studied, and in mammals aromatase is involved in the maturation of neurons and brain differentiation (Hutchison et al. 1997). The concentration of estradiol in the brain of Olive Ridley sea turtle embryos is much higher at feminizing temperatures than at masculinizing temperatures whereas the gonadal level of this steroid is identical at both temperatures (Salame-Mendez et al. 1998). Sexually dimorphic transcription of the aromatase gene has been detected in the brain of Malaclemys terrapin embryos during the early stages of sex determination, with a greater abundance in the female brain at the beginning of TSP (Jeyasuria \& Place 1998). Aromatase activity measurements in $T$. scripta, also revealed differences between male and female brains while identical levels were observed in the gonads at the same stage (Willingham et al. 2000). These results indicate that, at least in some TSD species, the brain could be the site of steroid hormone synthesis in response to temperature.

In the same way, in some fishes temperature could affect sex differentiation via steroid production modulation in the brain. Indeed, in the tilapia, Oreochromis mossambicus, before 10 days post hatching, high temperature significantly increases aromatase mRNA level in the brain while a lower temperature results in a decrease (Tsai et al. 2003). Sequential hermaphroditism is a common feature among marine fishes and in some species sex reversal is controlled by social cues. It seems reasonable to argue that in these species social stimuli are integrated by the brain and delivered to the whole body, especially the gonads.

In our amphibian model, $P$. waltl, little is known about aromatase in the brain. The present study was performed in order to get more information and to determine if cerebral aromatase could be affected by heat treatment as previously reported for the gonadal isoform.

\section{Materials and methods}

\section{Animals}

Adult $P$. waltl were reared in fresh water at $20 \pm 2{ }^{\circ} \mathrm{C}$ in our laboratory. ZZ larvae and one group of $\mathrm{ZW}$ larvae were maintained at $20{ }^{\circ} \mathrm{C} \pm 2{ }^{\circ} \mathrm{C} \quad\left(\mathrm{ZZ}^{20}\right.$ and $\mathrm{ZW}^{20}$ larvae), the 
temperature at which sexual genotype and sexual differentiation are concordant. Another group of ZW larvae was heat-treated at $32{ }^{\circ} \mathrm{C}$ during the TSP that extends from stage 42 to stage $55\left(\mathrm{ZW}^{32}\right.$ larvae); under this rearing temperature, all larvae differentiate into males. Developmental stages were determined by macroscopic observation according to Gallien and Durocher (1957). The sexual genotype of each individual was identified by electrophoretic patterning of the sex-linked peptidase-1, as described previously (Chardard et al. 1995).

Before dissection, animals were anesthetized in a solution of benzocaïne $(0.03 \%)$. In adult animals, aromatase expression was studied in the whole brain and in pieces of gonad. In larvae, the analyses were performed in the whole brain and in the gonad-mesonephros complex. Indeed, at most of the larval stages, gonads alone could not be dissected out due to their small size. In situ hybridization analyses have shown the absence of aromatase expression in the mesonephros (Kuntz et al. 2003b).

\section{P450 aromatase cDNA end isolation}

The 5' rapid amplification of cDNA end (RACE) system was used to amplify the $5^{\prime}$-end of brain P450 aromatase cDNA (SMART RACE cDNA Amplification Kit, Clontech). cDNA was synthesized from $1 \mu \mathrm{g}$ adult brain total RNA according to the manufacturer's instructions. PCR was performed with a specific primer for $\mathrm{P} 450$ aromatase (5'-CGGATGACGACGTCGACAACGCGGTG$\left.3^{\prime}\right)$. The reaction mixture was heated at $94{ }^{\circ} \mathrm{C}$ for $3 \mathrm{~min}$, amplified for the first five cycles at $94{ }^{\circ} \mathrm{C}$ for $30 \mathrm{~s}$ and $72{ }^{\circ} \mathrm{C}$ for $3 \mathrm{~min}$. The next five cycles were: $94{ }^{\circ} \mathrm{C}$ for $30 \mathrm{~s}, 70{ }^{\circ} \mathrm{C}$ for $30 \mathrm{~s}$ and $72{ }^{\circ} \mathrm{C}$ for $3 \mathrm{~min}$. The remaining 30 cycles of PGR were carried out at $94{ }^{\circ} \mathrm{C}$ for $30 \mathrm{~s}, 68^{\circ} \mathrm{C}$ for $30 \mathrm{~s}, 72^{\circ} \mathrm{C}$ for $3 \mathrm{~min}$ and a final extension at $72{ }^{\circ} \mathrm{C}$ for $10 \mathrm{~min}$. The amplified products were separated on a $1 \%$ agarose gel. A fragment of $1.2 \mathrm{~kb}$ was purified (QiaEX II Kit, Qiagen), inserted into the plasmid pGEM-T easy (Promega) and transfected into the E. coli TG1 strain. After extraction, the $1.2 \mathrm{~kb}$ fragment was restricted and subcloned into pBluescript $\mathrm{KS}^{+}$, and a $5^{\prime}$ region subclone was sequenced (Genome Express, Meylan, France). Two independent clones have been analyzed for 5' RACE P450 aromatase from adult brain.

\section{RT-PCR analyses}

The detailed protocol for reverse transcription has been described previously (Kuntz et al. 2003b). Total RNA was extracted from the different tissues using TRIzol reagent (Invitrogen) and quantified. Total RNA ( $3 \mu \mathrm{g}$ for adult tissue and larval brain; $1 \mu \mathrm{g}$ for larval gonad-mesonephros complex) was reverse transcribed using hexamer primers and 100 units MMLV reverse transcriptase (Invitrogen) in a $25 \mu \mathrm{l}$ total volume. A $2 \mu \mathrm{l}$ aliquot of resultant cDNA was used for PCR. The amplification was performed with $0 \cdot 1$ unit Taq DNA polymerase (Invitrogen) in PCR buffer containing $25 \mathrm{mM}$ of each dNTP, $2.5 \mathrm{mM} \mathrm{MgCl}_{2}$ and $0.4 \mathrm{pM}$ of each primer in a total volume of $25 \mu \mathrm{l}$.

Open reading frame $(\mathrm{ORF})$-specific primers for $P$. waltl total P450-aromatase were 5'ATTGGAGGACGTGA CACGAT- $3^{\prime}$ and 5'TTGTTCTGTAGATTCTC TAA- ${ }^{\prime}$ and led to a PCR product of $510 \mathrm{bp}$ in length (Kuntz et al. 2003b). This product encompasses two exon/intron boundaries based on other vertebrate aromatase genes. In order to amplify specifically the cerebral and the gonadal aromatase isoforms, we designed two primers specific for each $5^{\prime}$ untranslated region (5'-UTR): AROM-B, 5'-AGGGCAAGCAGTGG TAACAA-3', and AROM-G, 5'-ACGGGGGGA CACACTTCTTG - $3^{\prime}$, and one in the coding region AROM-BG, 5'-CTCGAGATGTAGTGT CAATG $-3^{\prime}$. The PCR products were 409 bp with AROM-B and 391 bp with AROM-G.

GAPDH was used as a control to ensure that the RNA was not degraded or to prevent poor transcription quality (primers 5'-ACTACAAAG GACTAGGTCAGG-3' and 5'-CGGGTATTGG ACTCAACGACG-3' leading to a 290 bp fragment). The PCR conditions were 1 min denaturation at $94{ }^{\circ} \mathrm{C}, 1 \mathrm{~min}$ annealing, 1 min elongation at $72{ }^{\circ} \mathrm{C}$. Annealing temperature was $52{ }^{\circ} \mathrm{C}$ for total aromatase and GAPDH. PCR conditions for the 5 '-part of aromatase were $30 \mathrm{~s}$ denaturation at $94^{\circ} \mathrm{C}$, $30 \mathrm{~s}$ annealing, $2 \mathrm{~min}$ elongation at $72{ }^{\circ} \mathrm{C}$. Annealing temperatures were $56^{\circ} \mathrm{C}$ for AROMB-BG and $58^{\circ} \mathrm{C}$ for AROM-G-BG. We used 35 cycles for qualitative analyses instead of 26 or 28 cycles for semi-quantitative analyses in gonads and brain respectively.

PCR products $(10 \mu \mathrm{l})$ were run in a $1 \%$ agarose gel and either observed directly or transferred to nylon membrane (Hybond-N, Amersham) before 
hybridization with digoxygenin (DIG)-labeled probes and detection by chemoluminescence using standard conditions (Kuntz et al. 2003b). The intensity of the hybridization signal was measured by the use of the GelDoc 2000 (Bio-Rad Laboratories) and a software package (Quantity One v.4.3.1, Bio-Rad Laboratories). The relative amounts of P450-aromatase mRNA were normalized to GAPDH.

\section{Aromatase activity measurement}

The activity of the enzyme was determined by the use of the tritiated water method as previously described (Ghardard et al. 1995). The radioactivity from tritiated water released by aromatization of $\left[1 \beta-{ }^{3} \mathrm{H}\right]$ androstenedione was measured and the enzymatic activity was calculated and expressed in femtomoles of estrone produced per hour.

\section{Statistical analysis}

The results are expressed as means \pm standard error of several experiments as indicated in the text. Data were analyzed by means of Student's $t$-test.

\section{Results}

\section{Isolation of a brain isoform of P450 aromatase cDNA}

Since two aromatase isoforms have been found in the brain and ovary of fish species, we hypothesized that a similar situation could exist in Pleurodeles. Hence, 5' RACE PGR was performed from total RNA extracted from adult brain. A clone of $1.2 \mathrm{~kb}$ was isolated and sequenced (Fig. 1). The entire coding region was similar to that of the isoform that we characterized previously from adult Pleurodeles' gonads (Kuntz et al. 2003b). However, the sequence of the $5^{\prime}$-UTR was different. Ovarian aromatase cDNA includes a short 5'-UTR of $45 \mathrm{bp}$ whereas that of brain aromatase cDNA is $83 \mathrm{bp}$ long. Only the $26 \mathrm{bp}$ upstream of the ATG initiation codon were identical.

\section{Tissue-specific expression of P450 aromatase in adult Pleurodeles}

The expression pattern of brain and ovarian aromatase mRNA isoforms in brain and gonads of adult animals was studied by qualitative RT-PGR (Fig. 2), using primers able to amplify specifically each of them (see Fig. 1). The two isoforms were detected both in brain and gonads although in different amounts: the brain isoform is mainly expressed in male and female brain whereas the ovarian form is predominantly detected in testis and ovary.

\section{Cerebral and gonadal expression of aromatase in Pleurodeles larvae}

In gonad-mesonephros complexes, aromatase mRNA could be detected using the gonad-specific primers whatever the sex of the larvae, the developmental stage or the rearing temperature (not shown). A semi-quantitative RT-PCR was performed at stage 55 using primers that amplify specifically the gonadal isoform (Fig. 3). We observed that the level of gonadal aromatase mRNA was significantly higher in $Z^{20}$ larvae than in $Z Z Z^{20}$ and $Z W^{32}$ larvae, reflecting what had already been observed using primers designed in the coding region (Kuntz et al. 2003b). In contrast, a low and sparse expression of the brain isoform was observed in larval gonads independently of sex and rearing temperature of larvae, even when a 35-cycle PGR was used (not shown).

In the brain, with 35 PGR cycles and primers specific for each aromatase isoform (AROM-B or AROM-G), signals were detected randomly in a few samples when using $3 \mu \mathrm{g}$ total RNA while both isoforms were observed when using $5 \mu \mathrm{g}$ total RNA (not shown). However, using $3 \mu \mathrm{g}$ total RNA and primers located in the ORF that allow the simultaneous amplification of both isoforms, total aromatase expression was observed in all samples (Fig. 4). Hence, study of aromatase expression in larval brain was performed using primers located in the ORF.

\section{P450 aromatase expression in the brain during TSP}

Aromatase expression in the brain was analyzed by qualitative RT-PCR during a window of development ranging from stage 42 to stage 55 including the TSP. We analyzed ZZ and ZW larvae but also ZW larvae which had been exposed to $32{ }^{\circ} \mathrm{C}$ since stage 42. Aromatase mRNAs were already detected in the brain at stage 42 . The level of aromatase 


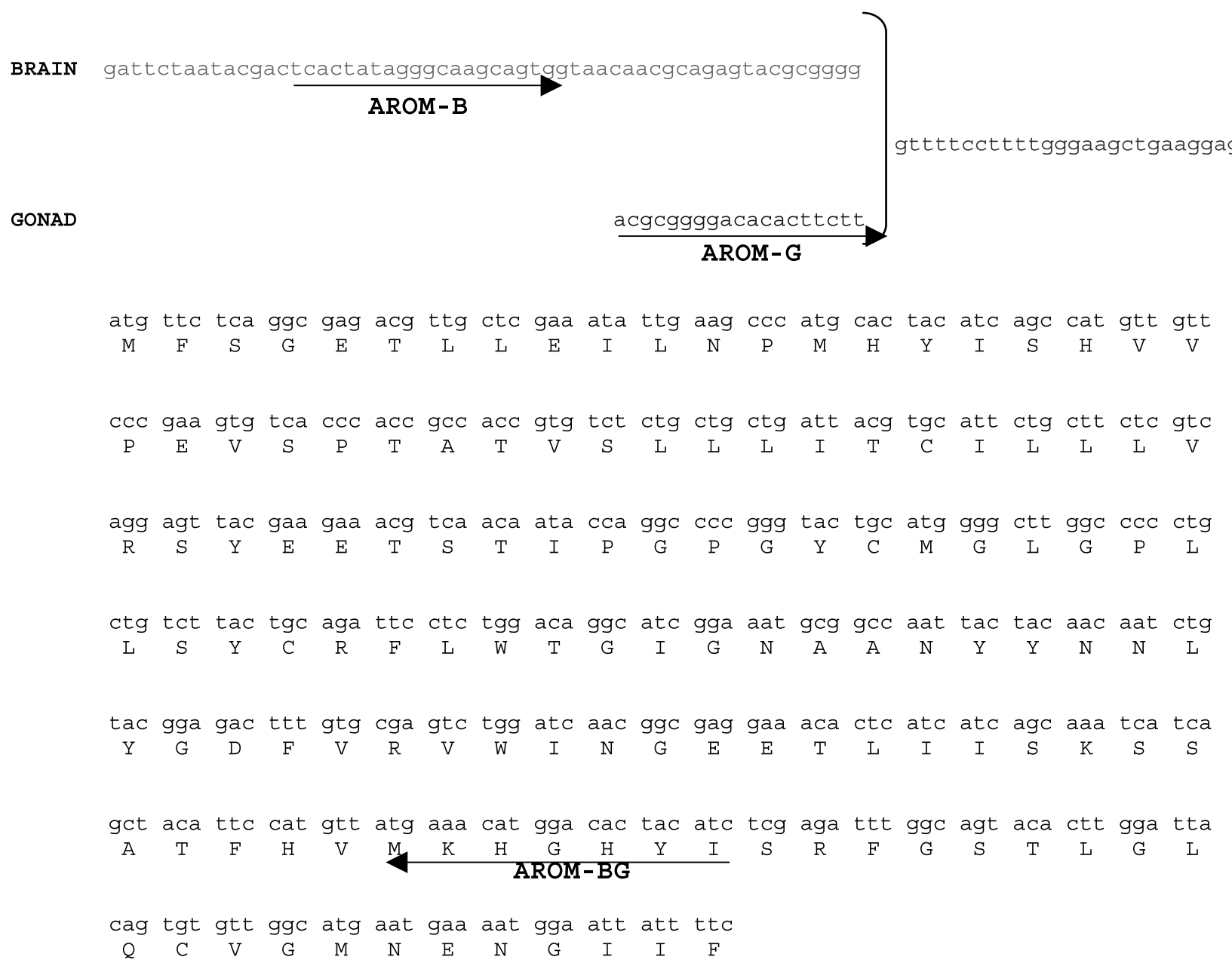

Figure 15 '-end sequences of Pleurodeles walt aromatase cDNA isoforms. The previously characterized ovarian aromatase $\mathrm{cDNA}$ is aligned with those isolated from adult Pleurodeles brain. The latter is longer than the ovarian form due to a different 5'-UTR. The primers used for different PCRs are arrowed.

expression appeared low at the first stages of TSP, however the expression was observed in the three types of larvae at all the stages studied (Fig. 4).

\section{Brain aromatase expression and activity are neither sex specific nor temperature sensitive}

The level of aromatase mRNAs in the brain of the different larvae was studied using semi-quantitative RT-PGR. In our previous studies we showed that, in the gonads, no difference in the level of aromatase expression between the different batches of larvae could be observed prior to stage 54 (Kuntz et al. 2003b). In the brain (Fig. 5A), aromatase expression was not significantly different between $Z^{20}$ and $Z W^{20}$ larvae either at stage 54 or at stage 55. Temperature has no effect on brain aromatase expression since no significant difference was observed between $\mathrm{ZW}^{20}$ and $\mathrm{ZW}^{32}$ larvae at both stages. In contrast, in gonad-mesonephros complexes, aromatase mRNA levels were $1 \cdot 5$-fold higher in $Z^{20}$ larvae than in $Z^{20}(P=0 \cdot 04)$ or $Z^{32}$ larvae $(P=0.006)$ at stage 54 (Fig. 5B). At stage 55 , the level of expression was $2 \cdot 8$-fold higher in $\mathrm{ZW}^{20}$ larvae than in $\mathrm{ZZ}^{20}\left(P=3 \cdot 10^{-6}\right)$ or $\mathrm{ZW}^{32}$ larvae $(P=0 \cdot 0003)$. No significant difference was observed between $Z^{20}$ larvae and $Z^{32}$ larvae at either stage.

Aromatase activity was measured in the whole brain of $Z^{20}$ and $Z^{20}$ larvae at stages 46, 50, 54 and 55 (Fig. 6A). Both sexes showed low activity with no difference between them at any stage 


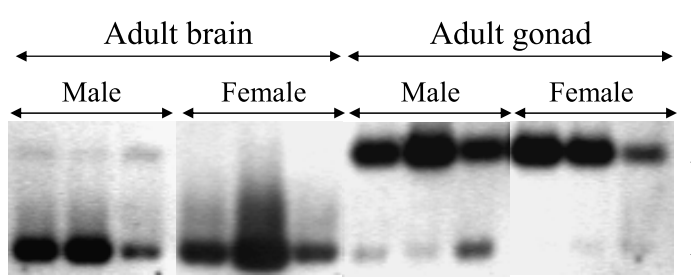

Arom G

Figure 2 Expression pattern of two aromatase isoforms in Pleurodeles waltl adult brain and gonads. Total RNA was extracted from brain and gonads of three adult males and three adult females, reverse transcribed and amplified by PCR for 35 cycles. Arom-B and Arom-G correspond to the brain and the ovarian isoform respectively.

tested. This result is in contrast to that observed in the differentiating gonads of the same individuals where a high difference appears between $\mathrm{ZZ}^{20}$ and $\mathrm{ZW}^{20}$ larvae at stages 54 and 55 (Fig. 6B).

\section{Discussion}

Steroids play a decisive role in non-mammalian vertebrate sex differentiation, especially estrogens in female differentiation. Treatment of embryos or larvae with estrogens or endocrine disruptors or mimetics are well known to induce sex reversal in all non-mammalian vertebrates. This has been observed in species where sex is genetically determined, including birds (Elbrecht \& Smith 1992), amphibians (Gallien 1962, Hayes 1998) and teleosts (Baroiller \& D'Cotta 2001). This also applies to species where temperature is the only known sex-determining factor (Pieau et al. 2001) or where temperature superimposes on a genetic sex determination system (Kuntz et al. 2003a). In these cases, a correlation between temperature and estrogen production has been described: efficiency periods of both factors are concordant and antagonistic effects of temperature and estrogens have been observed (Crews 1996, Pieau et al. 2001, Chardard et al. 2004). All these observations led to the hypothesis that temperature determines the steroidal environment of the gonads by negatively regulating aromatase. However, the site of temperature action is unknown: does it act directly on the gonad or on another target?

In some turtles (Thomas et al. 1992, SalameMendez et al. 1998, Willingham et al. 2000) and crocodilians (Smith \& Joss, 1994, Smith et al. 1995, Milnes et al. 2002), aromatase activity and expression in the gonads do not show any difference between males and females either before the end of TSP, or even later. In such species, differences between male and female embryos have been described in the brain, which is another major aromatase expressing organ. In the TSD turtle, Chelydra serpentina, aromatase mRNA level in the

\section{Gonadal aromatase expression}

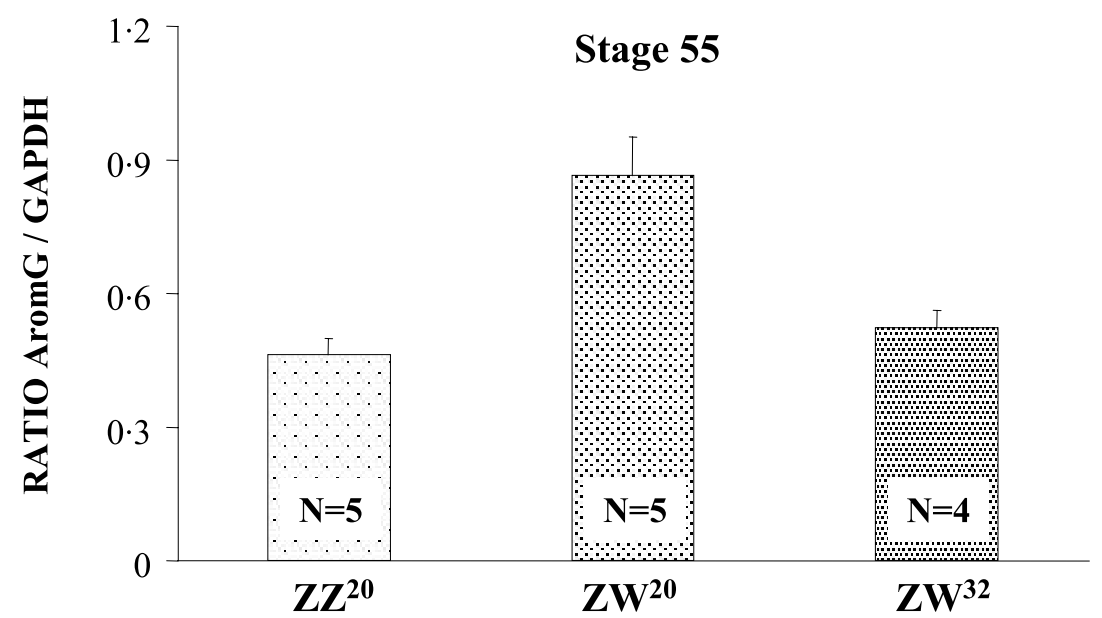

Figure 3 Semi-quantitative analysis of gonadal aromatase isoform expression in gonads of larvae at stage 55. The relative amount of P450-aromatase mRNA was normalized to GAPDH. Values are means of replicates (one replicate is a pool of five animals), the number of which is indicated by $\mathrm{N}$. Vertical bars indicate the mean standard error. 


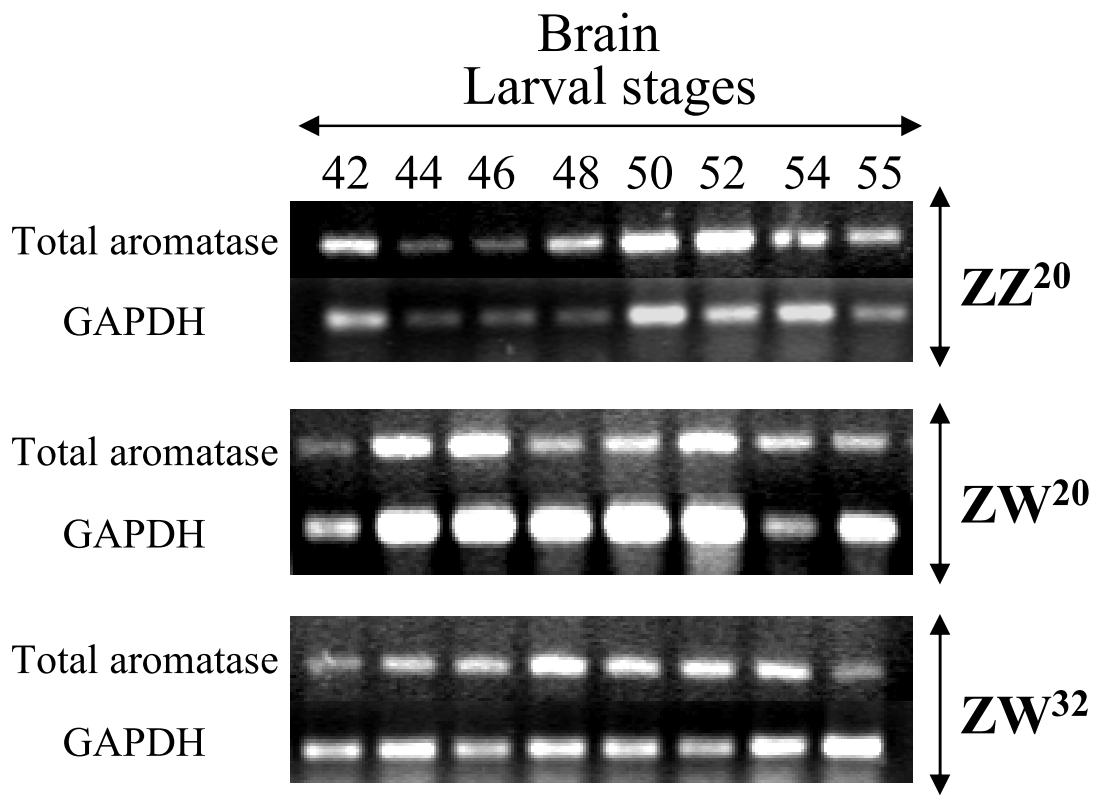

Figure 4 Qualitative RT-PCR analysis of total P450 aromatase expression in the brain of Pleurodeles larvae. The presence of P450 aromatase transcripts was studied at different stages: 42, 44, 46, 48, 50, 52, 54, 55. Total RNA was isolated from brain larvae, reverse transcribed and amplified by PCR for 35 cycles with ORF-specifc primers. Three kinds of larvae were used: $Z^{20}, Z^{20}$ and $Z^{32}$. GAPDH served as a positive control.

brain is higher at masculinizing temperatures than at feminizing temperatures (Place et al. 2001). Conversely, in other thermosensitive species, aromatase is female specific in the brain. In the TSD turtle, M. terrapin, aromatase mRNA level is higher at feminizing temperatures than at masculinizing temperatures and this difference arises earlier than in the gonads (Jeyasuria \& Place 1998). The same result has been obtained at the activity level in another turtle, T. scripta (Willingham et al. 2000). In the same way, in the fish tilapia, brain aromatase activity is higher in females than in males and these differences are sensitive to sex-reversing temperatures (D'Cotta et al. 2001, Tsai et al. 2003). In all these species, temperature could act directly on the brain which would then transfer the information to the gonad; indeed, the central nervous system mediates physiological responses to many environmental factors in post natal organisms. However, the link between brain and gonads during sex differentiation needs further investigation.

In mammals, the aromatase encoding gene, cyp19, has multiple tissue-specific promoters and alternative first exons (Simpson et al. 1994). In fishes, there are at least two distinct cyp19 loci, cyp19b/P450 aromB expressed at high levels in the brain and cyp19a/P450 aromA expressed at high levels in the ovary (Tchoudakova \& Callard 1998, Kishida \& Callard 2001). In the present work, we identified in Pleurodeles two cDNA encoding aromatases which differ only in their 5'-UTR, suggesting the use of an alternative untranslated exon 1 such as observed in mammals. In adults, the first isoform, AROM-G, is expressed at a high level in the gonads and at a low level in the brain, while the other one, AROM-B is highly expressed in the brain.

However, in the brain of larvae, we have detected expression of both isoforms when using specific primers and a high amount of total RNA. This result was also obtained by using lower amounts of total RNA with non-specific primers located inside the aromatase ORF. Together, these results suggest that both brain and gonadal aromatase are expressed in larval brain but at a very low level. Moreover, in our hands many RNAs seemed to be truncated which would explain 


\section{(A) Brain aromatase expression}

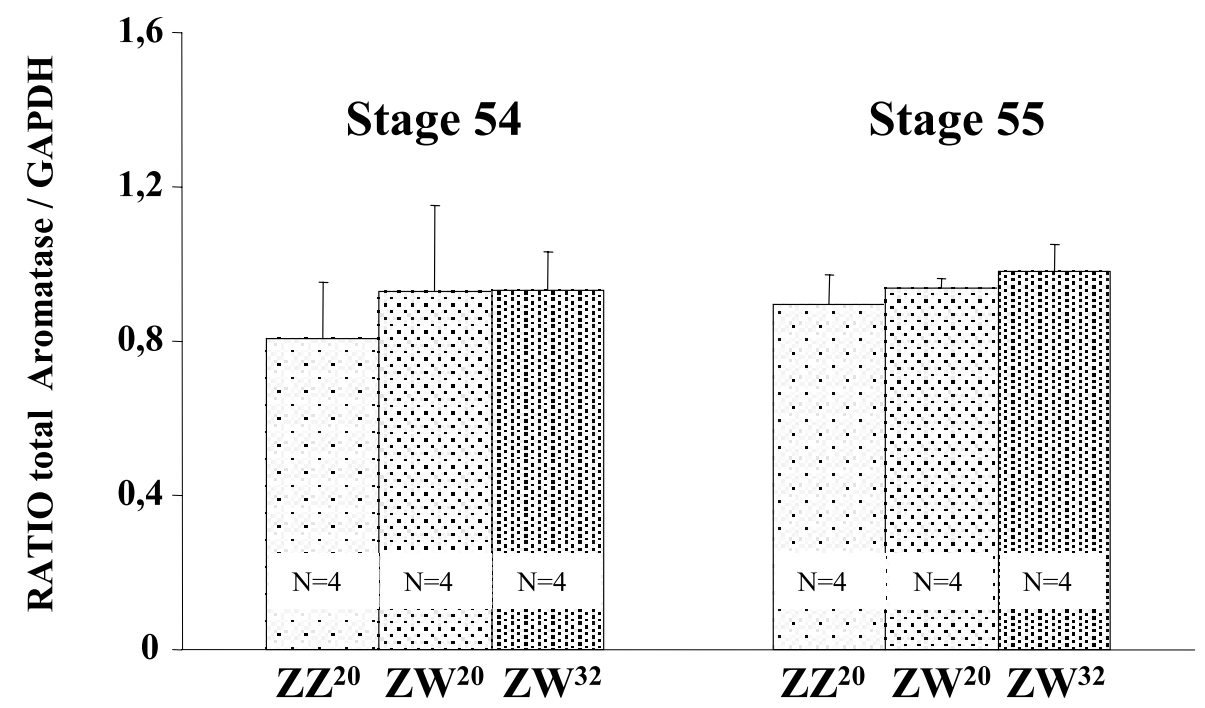

(B) Gonadal aromatase expression

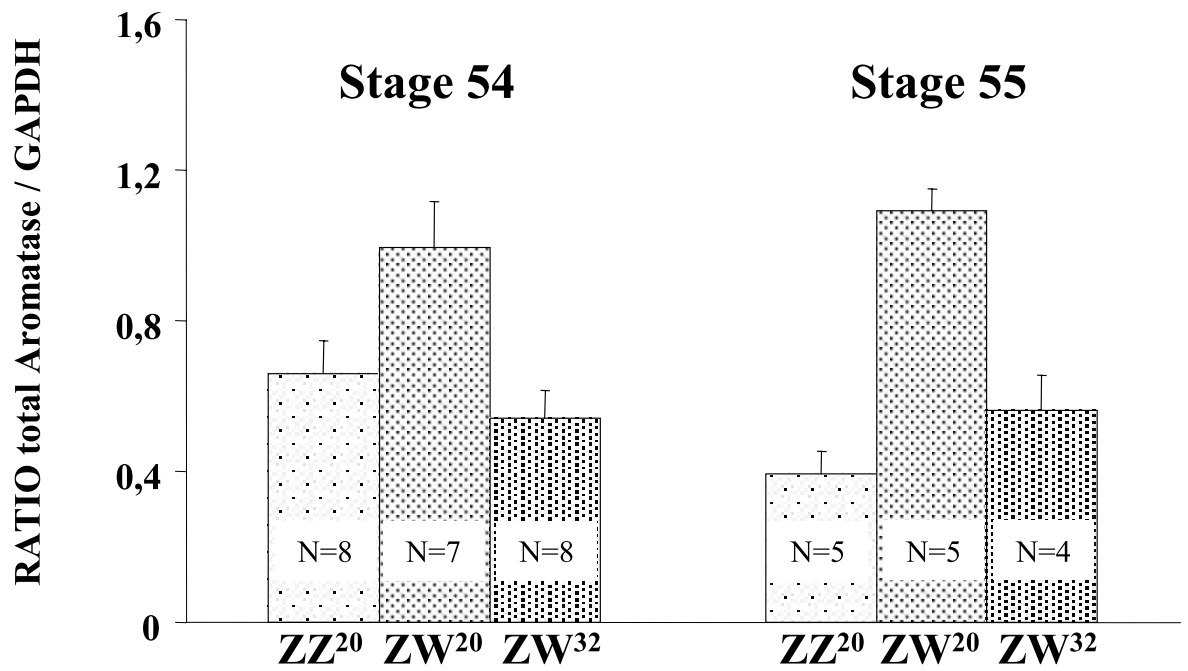

Figure 5 Semi-quantitative RT-PCR analysis of total aromatase expression in (A) brain and (B) mesonephros+gonads of larvae at stages 54 and 55 . ORF-specific primers were used and the relative amount of P450-aromatase mRNA was normalized to GAPDH. Values are means of replicates (one replicate is a pool of four animals for the brain, five animals for the mesonephros+gonad), the number of which is indicated by N. Vertical bars indicate the mean standard error.

the better results obtained with ORF-specific primers than with $5^{\prime}$-UTR-specific ones. One might also suggest that a larval brain-specific aromatase isoform exists in $P$. waltl. Although this cannot be ruled out completely, to our knowledge such a situation has never been described in other vertebrate species.

We found early aromatase expression, as early as the beginning of TSP at stage 42 , in the brain as observed for the gonads (Kuntz et al. 2003b). 


\section{(A) Brain aromatase activity}

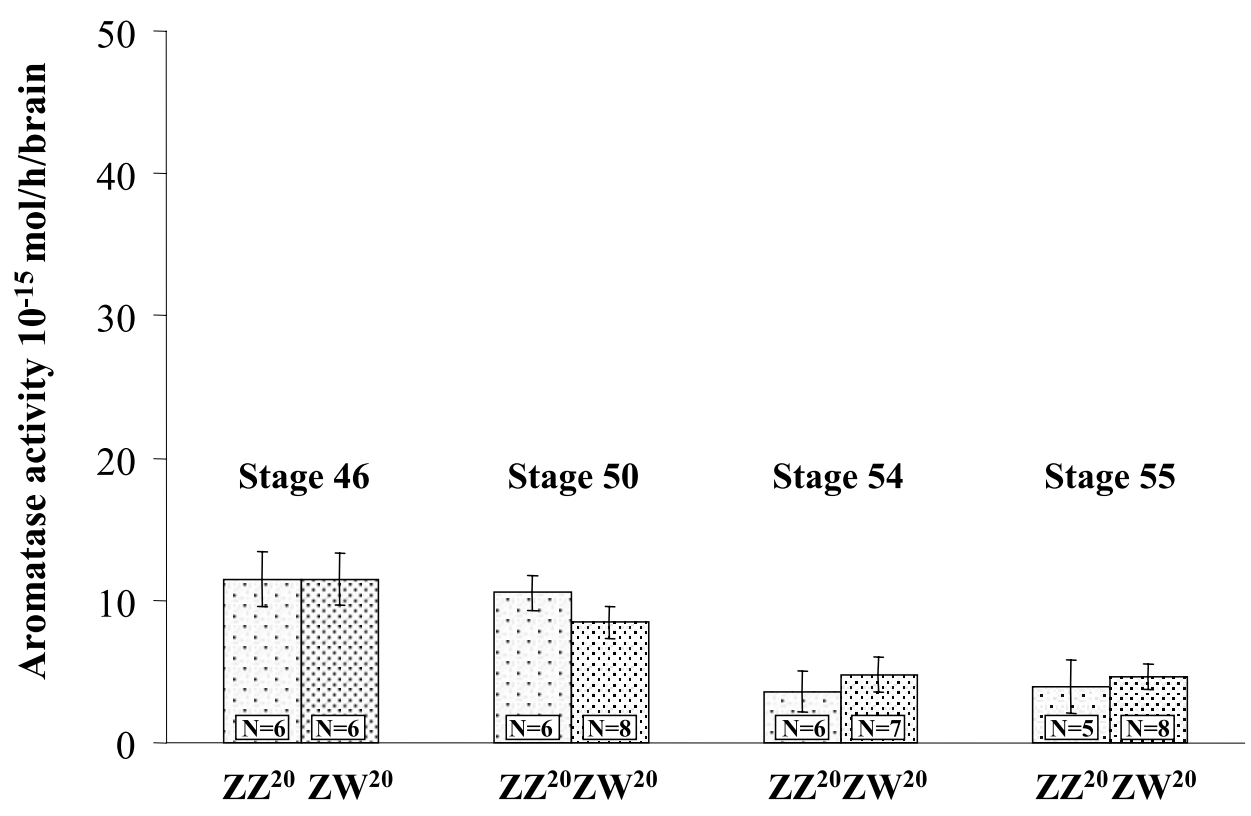

\section{(B) Gonadal aromatase activity}

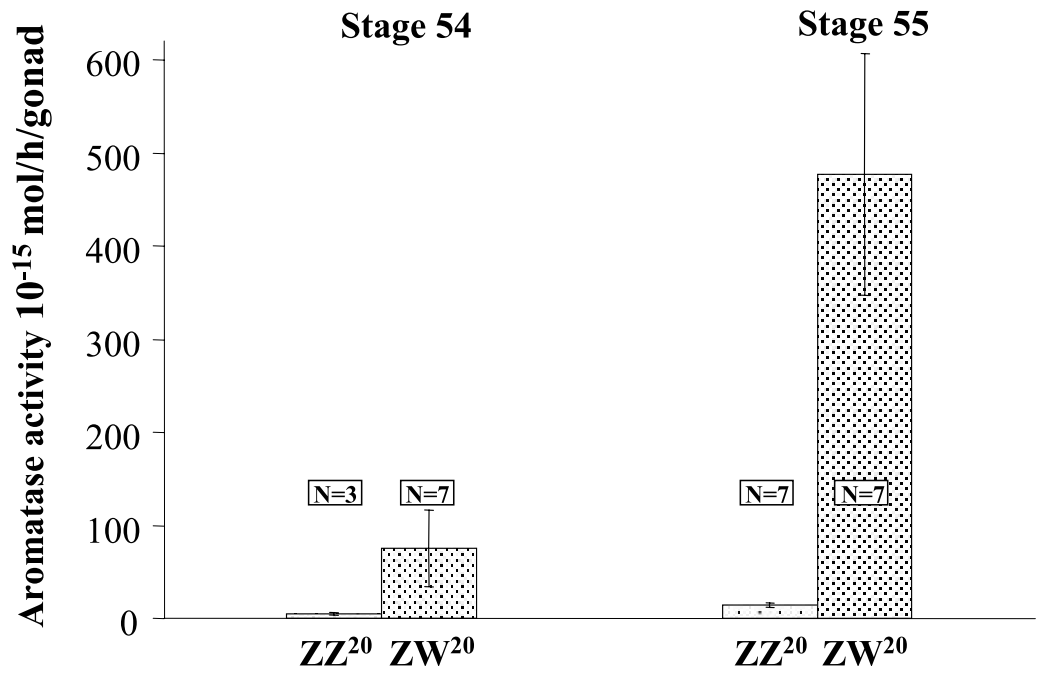

Figure 6 Aromatase activity in (A) whole brain and (B) mesonephros+gonads of Pleurodeles larvae. Activity was measured with the tritiated water method and expressed in femtomoles of estrone produced/h/organ. Values are means of replicates (one animal/replicate), the number of which is indicated by $\mathrm{N}$. Vertical bars indicate the mean standard error.

However, in contrast to the gonads, we did not find any difference between the brains of male and female larvae in their level of aromatase transcripts. Activity measurements confirmed this: a low activity, comparable to the activity of male gonads, is detected with no difference between males and females either during TSP (stages 46 and 50) or at the end of this period (stages 54 and 55) when ovarian differentiation is already initiated. In the same way, in $A$. mississipiensis, no difference in 
aromatase activity was detected in the brain until late TSP, as observed in gonads. Moreover, embryos incubated at male-producing temperatures and treated simultaneously with estradiol develop as females with an intermediate aromatase activity in gonads and a masculinized brain activity. This does not support an effect of the brain on gonad differentiation in the alligator (Milnes et al. 2002). Decapitation experiments in embryos of two other species of reptiles had already suggested that gonadal sex determination is independent of the brain (Raynaud 1962, Dufaure 1966). If this is a general case for vertebrates, differences in aromatase-expressing cells in the brain of thermosensitive species could simply reflect sex differentiation of the brain itself. Indeed, estrogen-sensitive (estrogen receptor expressing) and estrogen-forming (aromatase expressing) networks of neurons have been described in a large number of species. For example, in mammals, where gonadal differentiation is steroid independent, there is a sex difference in aromatase expression in the developing brain (Hutchison et al. 1997).

In $P$. waltl, we observed that aromatase expression was not different between $\mathrm{ZW}^{20}$ and $\mathrm{ZW}^{32}$ brain larvae in contrast to the downregulation observed in gonads of heat-treated larvae. This suggests that temperature has no effect on brain aromatase and excludes the brain as a temperature-sensitive organ inducing gonadal sex differentiation as a secondary event. In the same way, in the turtle $L$. olivacea, the expression of SOX9, a testis differentiation gene, is regulated by temperature in isolated gonads in culture, showing that gonads have an autonomous temperature detector (Moreno-Mendoza et al. 2001). Experiments on isolated gonads are actually under investigation in order to clarify the role of the brain in thermal sex reversal of $P$. waltl.

\section{Acknowledgments}

We would like to thank $\mathrm{M}$ Callier for technical assistance, J Magdalou and M-H Piet for their help in radioactivity measurements and $\mathrm{F}$ Kuepper for reading the manuscript. These studies were supported by grants of the Ligue Contre le Cancer (Comités de la Meurthe et Moselle, de la Meuse et des Vosges), of the Association pour la Recherche sur le Cancer, of the Conseil Régional de Lorraine and of the Université Henri Poincaré.

\section{References}

Baroiller JF \& D'Cotta H 2001 Environment and sex determination in farmed fish. Comparative Biochemistry and Physiology 130 399-409.

Chardard D \& Dournon C 1999 Sex reversal by aromatase inhibitor treatment in the newt Pleurodeles waltl. Fournal of Experimental Zoology $28343-50$

Chardard D, Desvages G, Pieau C \& Dournon C 1995 Aromatase activity in larval gonads of Pleurodeles waltl (Urodele Amphibia) during normal sex differentiation and during sex reversal by thermal treatment effect. General and Comparative Endocrinology 99 100-107.

Chardard D, Kuntz S, Chesnel A \& Flament S 2003 Effects of androgens on sex differentiation of the urodele Pleurodeles waltl. Journal of Experimental Zoology 296 46-55.

Chardard D, Penrad-Mobayed M, Chesnel A, Pieau C \& Dournon C 2004 Thermal sex reversals in amphibians. In Temperature Dependent Sex Determination. pp 59-67 Eds N Valenzuela \& V Lance. Washington, DC, USA: Smithsonian Institution Press.

Crews D 1996 Temperature dependent sex determination: the interplay of steroid hormones and temperature. Zoological Science $\mathbf{1 3}$ $1-13$.

Crews D, Bergeron JM, Bull JJ, Flores D, Tousignant A, Skipper JK \& Wibbels T 1994 Temperature dependent sex determination in reptiles: proximate mechanisms, ultimate outcomes and practical applications. Developmental Genetics 15 297-312.

D'Gotta H, Fostier A, Guiguen Y, Govoroun M \& Baroiller JF 2001 Aromatase plays a key role during normal and temperature-induced sex differentiation of tilapia Oreochromis niloticus. Molecular Reproduction and Development 59 265-276.

Dournon C \& Houillon C 1985 Thermosensibilité de la différenciation sexuelle chez l'Amphibien Urodè le, Pleurodeles waltlii Michah. Conditions pour obtenir l'inversion du phénotype sexuel de toutes les femelles génétiques sous l'action de la température d'élevage. Reproduction Nutrition Développement $\mathbf{2 5}$ 671-688.

Dufaure JP 1966 Recherches descriptives et expérimentales sur les modalités et facteurs du développement de l'appareil génital chez le lézard vivipare (Lacerta vivipara, Jacquin) Archives d'Anatomie, Microscopie, Morphologie Expérimentale 55 437-537.

Elbrecht A \& Smith RG 1992 Aromatase enzyme activity and sex determination in chickens. Science 255 467-470.

Gallien L 1962 Comparative activity of sexual steroids and genetic constitution in sexual differentiation of amphibian embryos. General and Comparative Endocrinology Suppl $1346-355$.

Gallien L \& Durocher M 1957 Table chronologique du développement chez Pleurodeles waltl. Bulletin Biologique France et Belgique 91 97-114.

Hayes T 1998 Sex determination and primary sex differentiation in amphibians: genetic and developmental mechanisms. Fournal of Experimental Zoology 281 373-399.

Hutchison JB, Beyer C, Hutchison RE \& Wozniak A 1997 Sex differences in the regulation of embryonic brain aromatase. Fournal of Steroid Biochemistry and Molecular Biology 61 315-322.

Jeyasuria P \& Place A 1998 Embryonic brain-gonadal axis in temperature-dependent sex determination of reptiles: a role for P450 aromatase (CYP19). Fournal of Experimental Zoology 281 428-449.

Kishida M \& Callard GV 2001 Distinct cytochrome P450 aromatase isoforms in zebrafish (Danio rerio) brain and ovary are differentially 
programmed and estrogen regulated during early development. Endocrinology 142 740-750.

Kuntz S, Chardard D, Chesnel A, Grillier-Vuissoz I \& Flament S $2003 a$ Steroids, aromatase and sex differentiation of the newt Pleurodeles waltl. Cytogenetics and Genome Research 101 283-288.

Kuntz S, Chesnel A, Duterque-Coquillaud M, Grillier-Vuissoz I, Callier M, Dournon C, Flament S \& Chardard D $2003 b$ Differential expression of P450 aromatase during gonadal sex differentiation and sex reversal of the newt Pleurodeles waltl. Fournal of Steroid Biochemistry and Molecular Biology 84 89-100.

Milnes MR, Roberts RN \& Guillette LJ 2002 Effects of incubation temperature and estrogen exposure on aromatase activity in the brain and gonads of embryonic alligators. Environment and Health Perspectives 110 (Suppl 3) 393-396.

Moreno-Mendoza N, Harley VR \& Merchant Larios H 2001 Temperature regulates SOX9 expression in cultured gonads of Lepidochelys olivacea, a species with temperature sex determination. Developmental Biology 229 319-326.

Pieau C, Dorizzi M \& Richard-Mercier N 2001

Temperature-dependent sex determination and gonadal differentiation in reptiles. In EXS91 Genes and Mechanisms in Vertebrate Sex Determination, pp 117-141. Eds G Scherer \& M Schmid M. Basel, Boston, Berlin: Birkhauser.

Place AR, Lang J, Gavasso S \& Jeyasuria P 2001 Expression of P450 arom in Malaclemys terrapin and Chelydra serpentina: a tale of two sites. Fournal of Experimental Zoology 290 673-690.

Raynaud A 1962 Le développement de l'embryon d'orvet (Anguis fragilis L.) décapité à un stade précoce. Comptes Rendus des Séances de l'Académie des Sciences de Paris 255 3041-3043.

Salame-Mendez A, Herrera-Munoz J, Moreno-Mendoza N \& Merchant-Larios H 1998 Response of diencephalon but not the gonad to female-promoting temperature with elevated estradiol levels in the sea turtle Lepidochelys olivacea. Fournal of Experimental Zoology $280304-313$.
Simpson ER, Mahendroo MS, Means GD, Kilgore MW, Hinshelwood MN, Graham-Lorence S, Amarneh B, Ito Y, Fisher CR, Michael MD, Mendelson CR \& Bulun SE 1994 Aromatase cytochrome P450, the enzyme responsible for estrogen biosynthesis. Endocrine Reviews 15 342-355.

Smith CA \& Joss JM 1994 Steroidogenic enzyme activity and ovarian differentiation in the saltwater crocodile, Crocodylus porosus. General and Comparative Endocrinology 93 232-245.

Smith CA, Elf PK, Lang JW \& Joss JMP 1995 Aromatase enzyme activity during gonadal sex differentiation in alligator embryos. $\mathbf{5 8}$ 281-290.

Tchoudakova A \& Callard GV 1998 Identification of multiple CYP19 genes encoding different cytochrome P450 aromatase isozymes in brain and ovary. Endocrinology 139 2179-2189.

Thomas EO, Licht P, Wibbels T \& Crews D 1992 Hydroxysteroid dehydrogenase activity associated with sexual differentiation in embryos of the turtle Trachemys scripta. Biology of Reproduction $\mathbf{4 6}$ 140-145.

Tsai CL, Chang SL, Wang LH \& Chao TY 2003 Temperature influences the ontogenic expression of aromatase and estrogen receptor mRNA in the developing tilapia (Oreochromis mossambicus) brain. Journal of Neuroendocrinology 15 97-102.

Willingham E, Baldwin R, Skipper JK \& Crews D 2000 Aromatase activity during embryogenesis in the brain and adrenal-kidney-gonad of the red-eared slider turtle, a species with temperature-dependent sex determination. General and Comparative Endocrinology 119 202-207.

Zaborski P 1986 Temperature and estrogen dependent changes of sex phenotype and HY antigen expression in gonads of a newt. In Progress in Developmental Biology, Part A, pp 163-169. Alan R Liss, Inc.

Received in final form 27 July 2004 Accepted 9 August 2004 